\title{
BMJ Open Does industry-sponsored education III foster overdiagnosis and overtreatment of depression, osteoporosis and over- active bladder syndrome? An Australian cohort study
}

\author{
Barbara Mintzes, ${ }^{1}$ Swestika Swandari, ${ }^{2}$ Alice Fabbri, ${ }^{1,3}$ Quinn Grundy, ${ }^{1}$ \\ Ray Moynihan, ${ }^{4}$ Lisa Bero ${ }^{1}$
}

This article has received a badge for Open data.

To cite: Mintzes B, Swandari S, Fabbri A, et al. Does industrysponsored education foster overdiagnosis and overtreatment of depression, osteoporosis and overactive bladder syndrome? An Australian cohort study. BMJ Open 2018;8:e019027. doi:10.1136/ bmjopen-2017-019027

- Prepublication history and additional material for this paper are available online. To view these files, please visit the journal online (http://dx.doi. org/10.1136/bmjopen-2017019027).

Preliminary study results were presented at the Preventing Overdiagnosis Conference in Barcelona, Spain, September 2016.

Received 6 August 2017 Revised 25 October 2017 Accepted 28 November 2017

Check for updates

For numbered affiliations see end of article.

Correspondence to Dr Barbara Mintzes; barbara.mintzes@sydney.edu.au

\section{ABSTRACT}

Objectives To investigate patterns of industry-sponsored educational events that focus on specific health conditions for which there are concerns about overdiagnosis and overtreatment.

Design and setting This retrospective cohort study examines publicly reported industry-sponsored events in Australia from October 2011 to September 2015 for three conditions potentially subject to overdiagnosis and overtreatment: depression, osteoporosis and overactive bladder. We used a database of transparency reports to identify events with a focus on depression, osteoporosis and overactive bladder and compared these with other sponsored events. We hypothesised that companies marketing treatments for each condition would sponsor related events and that target audiences would mainly work in primary care, reflecting a broad patient population. Main outcome measures Event and attendee characteristics, sponsoring companies, related marketed treatments, cost-effectiveness ratings and dispensing rates.

Results Over the study period, we identified 1567 events focusing on depression, 1375 on osteoporosis and 190 on overactive bladder (total $n=3132$, with 96660 attendees). These events were attended by primary care doctors more often than sponsored events without a focus on these three conditions: relative risk (RR) $=3.06(95 \% \mathrm{Cl} 2.81$ to 3.32 ) for depression, $\mathrm{RR}=1.48(95 \% \mathrm{Cl} 1.41$ to 1.55$)$ for osteoporosis and $\mathrm{RR}=2.59$ (95\% Cl 2.09 to 3.21) for overactive bladder. Servier, which markets agomelatine and AstraZeneca (quetiapine) sponsored $51.2 \%$ and $23.0 \%$ of depression events, respectively. Amgen and GlaxoSmithKline, which co-market denosumab, sponsored $49.5 \%$ of osteoporosis events and Astellas and Commonwealth Serum Laboratories (CSL) (mirabegron and solifenacin) sponsored $80.5 \%$ of overactive bladder events. Conclusions This 4-year overview of industry-sponsored events on three overdiagnosed and overtreated conditions found that primary care clinicians were often targeted, dinner was often provided and that a few companies sponsored most events. In most cases, sponsors' products are not cost-effective choices for the specified condition. This pattern highlights the need for professional education to be free of commercial sponsorship.
Strengths and limitations of this study

- Australia's transparency reports of industry funding of health professionals were unique internationally until 2015, in that the focus was on sponsored events.

- This is the first data-driven national analysis of condition-specific industry educational event sponsorship for overdiagnosed and overtreated conditions.

- Classification of events was blinded to sponsor, attendee characteristics and event descriptions.

- For each condition, we examined trends over time in sales and dispensing of lead sponsors' relevant marketed drugs, but we could not assess causal links between increased prescribing and event attendance, as no information was publicly available on the identity of individual event participants.

- Limited detail was available on the content of sponsored events; therefore, despite a sensitive search, we may have missed some relevant events per condition.

\section{INTRODUCTION}

The role of pharmaceutical industry sponsorship of health professional education has been subject to considerable controversy. There is disagreement about whether sponsored education is primarily promotional or educational. It has been described on the one hand as 'marketing masquerading as education' ${ }^{1}$ and on the other, if accompanied by proper controls, as able to meet the goal of "needs based, relevant, accessible education that is balanced and unbiased and improves healthcare outcomes. ${ }^{2}$

This controversy extends to how treatment outcomes are discussed and how conditions are defined. Messages in commercially sponsored education may exaggerate prevalence and/or attempt to medicalise 
aspects of ordinary life. Identified 'marketing messages' in continuing medical education (CME) for low female sexual desire included statements that it is 'very common and underdiagnosed' and that 'women may not be aware that they are sick or distressed. ${ }^{3}$ Similarly, US CME sponsored by a testosterone manufacturer supported a broader definition of hypogonadism than in listed indications for testosterone. ${ }^{4}$

A sponsored CME campaign can reach many health professionals, with potential widespread effects on practice. Purdue Pharma's launch of the opioid analgesic oxycodone in the USA included over 20000 sponsored educational events, many of which targeted general practitioners (GPs), potentially contributing to more opioid use in primary care. ${ }^{5}$

These are product-specific examples of sponsored CME that received media attention and may not reflect broader trends. There has been little exploration of the link between sponsored CME and specific conditions prone to overdiagnosis. Overdiagnosis, the detection of conditions unlikely to lead to ill health, disability or death in the absence of treatment, has been characterised as a 'modern epidemic'. ${ }^{67}$ It can lead to harm from adverse effects of treatments from which a person is unlikely to benefit, to psychological harm if a healthy person suffers from anxiety or stigma due to disease labelling and to harm to society through higher healthcare costs. There is evidence of commercial influence on overdiagnosis in a range of conditions through direct and indirect marketing aiming to establish the need for a product. ${ }^{7}$ One consequence of overdiagnosis is overtreatment, as overdiagnosis expands the pool of potentially treatable patients beyond thresholds at which treatment has been shown to be beneficial. The wide ranging influence of industries that benefit from expanded markets has been highlighted as a key driver. ${ }^{8}$

National patterns of industry sponsorship can shed light on controversies concerning the role of sponsored CME. From 2007 to late 2015, members of Medicines Australia, the national pharmaceutical industry trade association, were required by law to report on sponsored events for health professionals. ${ }^{9}$ These are described by Medicines Australia as 'educational events' and include both accredited CME and a large range of events without accreditation. ${ }^{10}$

Australia was one of the first countries to require the pharmaceutical industry to publicly report financing of hospitality for health professionals. In 2007, the Australian Competition Tribunal required Medicines Australia - who at the time opposed the move-to introduce mandatory disclosure of industry-sponsored events for health professionals following recommendations by the Australian Competition and Consumer Commission (ACCC). Unlike other countries relying on industry self-regulation of drug promotion via national industry associations, Australia has what could be described as a quasi-regulatory system, requiring approval of self-regulatory standards by a public regulatory body, the ACCC. ${ }^{11}$
These data provide a unique opportunity to examine the link between condition-specific sponsored events and companies marketing medicines for a condition. Over this 4-year period, 116845 events are described, varying in scope from a half-hour journal club in a hospital meeting room to several-day conferences, sometimes held overseas. ${ }^{12}$

We report here on event sponsorship with a focus on three conditions highlighted in the medical literature as potentially subject to overdiagnosis and overtreatment: depression, ${ }^{13}$ osteoporosis ${ }^{14}$ and overactive bladder. ${ }^{15} \mathrm{We}$ hypothesise that companies marketing drugs for these conditions are more likely to sponsor events with a focus on that condition than other companies. We also hypothesise that these events tend to target primary care practitioners who are likely to treat milder disease states than specialists. To test these hypotheses, we compare characteristics of the events focusing on these three conditions with other events sponsored by companies during the 4-year study period.

To investigate clinical implications, we examine whether sponsors' products were judged to be cost-effective and are covered under Australia's Pharmaceutical Benefits Schemes (PBS). The PBS was introduced in 1948 to subsidise the costs of outpatient medicines for the entire Australian population. The aim is to provide affordable access to needed medicines. An expert committee, the Pharmaceutical Benefits Advisory Committee (PBAC), recommends listing of medicines based on cost-effectiveness considerations that include both therapeutic gains and price. Medicines not listed on the PBS tend to have very limited sales.

We assess sponsorship patterns per condition in terms of audience, clinical versus non-clinical setting and provision of meals. We examine how often events included company-sponsored dinners as events with dinners provided are often held at restaurants and represent a higher value gift. For products for which there was a shift in which company held distribution rights over the study period, we also examine timing of event sponsorship in relation to distribution rights.

\section{METHODS}

\section{Data sources}

We downloaded 301 publicly available company reports covering the period from October 2011 to September 2015 from the Medicines Australia website (www.medicinesaustralia.com.au), converted them from PDF into Excel files, cleaned the data and resolved discrepancies. For example, we removed text from columns that should have contained numeric values only (eg, total cost) and, for a small minority of events, corrected totals equal to less than reported component costs.

These reports include the sponsoring company, timing, event description, venue type, number and profession of attendees, hospitality costs and total event costs. Coding methods are described in detail elsewhere. ${ }^{12} \mathrm{We}$ 
developed a retrospective cohort of sponsored events based on timing of sponsorship per company over time. A descriptive overview of the data on sponsored events has been published, ${ }^{12}$ and the dataset used for this analysis is available at http://dx.doi.org/10.4227/11/ 592631 edbd9d5.

We obtained a list of brands sold in Australia for each condition from the Australian Medicines Handbook ${ }^{16}$ and manufacturers' websites and annual dispensing data for publicly reimbursed drugs through Australia's PBS at http://www.pbs.gov.au/info/browse/statistics\#AS. For non PBS-subsidised drugs, sales volume data were obtained through Quintiles IMS.

We examined volume of use using annual numbers of dispensed prescriptions for PBS-subsidised drugs and numbers of units sold to retail and hospital pharmacies for non PBS-subsidised drugs.

\section{Selection of targeted conditions}

We chose depression, osteoporosis and overactive bladder as illustrative case studies of conditions for which diagnostic thresholds and treatment have extended beyond levels at which patients are likely to benefit. We selected these conditions a priori before carrying out any analyses.

Depression screening leads to many false positives, ${ }^{17} 18$ and many patients prescribed antidepressants in primary care fail to meet diagnostic criteria for major depression, ${ }^{19}$ a phenomenon that has been described as 'medicalising sadness' ${ }^{13}$ In 2013, Australia had one of the highest rates of antidepressant use among Organisation for Economic Cooperation and Development (OECD) countries. ${ }^{20}$

Questions have also been raised about diagnostic criteria for osteoporosis and the role of bone densitometry in greatly expanding the treatable population, primarily when used in screening of asymptomatic postmenopausal women and as a diagnostic tool for women with low-trauma fractures. Bone density screening is poorly predictive of clinical fractures, and a focus on bone density rather than fragility fractures has led to many more diagnoses. ${ }^{14}$ Further treatment expansion has occurred through lowered thresholds for 'pre-osteoporosis' and 'osteopenia', which further extend disease labelling to populations that fail to meet established criteria for a diagnosis of osteoporosis.

An 'imprecise' symptom-based definition of overactive bladder, largely linked to commercial interests, has replaced urodynamically confirmed bladder instability. ${ }^{15}$ Tolterodine, marketed by Pharmacia, was the first drug approved for overactive bladder symptoms. In 2002, Pharmacia's vice president described a threefold expansion of the treatable population through a definition of overactive bladder no longer requiring urinary incontinence. $^{21}$

Drug treatments for these three conditions have been heavily advertised to the public in the USA, with advertising that relies heavily on emotional appeals, targets women and tends to blur the boundaries between normal life and medical conditions requiring treatment. ${ }^{22}$

\section{Coding of Medicines Australia data on sponsored events}

An initial coding scheme for industry-sponsored events included sponsoring company, location, attendee profession, clinical focus, type of hospitality (such as whether meals or travel and accommodation were provided) and a set of relevant keywords to search unstructured text. ${ }^{12}$ We designed an additional coding scheme to identify events focusing on the three included conditions. The research team iteratively developed keywords based on disease names/symptoms and drug classes and products sold in Australia (generic and brand names) for each condition. Keywords were used to search unstructured text in the 'Description of function' column of reports. All relevant keywords associated with one or more events listed in the database were retained in the final coding scheme (see online supplementary appendix tables 1 and 2). During coding, we concealed other variables (using Excel's 'Column Hide' function) to blind the coder (SS) to sponsor, attendee characteristics and event descriptors.

\section{Analysis}

For each included condition, we provide a detailed analysis for all companies sponsoring at least $5 \%$ of events. We examined whether these companies market drugs to treat the condition and PBS reimbursement status for these drugs. We present frequency tables for event and attendee characteristics. Costs are reported in Australian dollars. We performed $\chi^{2}$ analyses to compare events per condition with other sponsored events using SPSS V.22.

\section{RESULTS}

Over the 4-year study period, we identified 3132 events focusing on the three conditions, with 96620 attendees. This included 1567 events with a focus on depression, with 41474 attendees; 1375 on osteoporosis with 33916 attendees and 190 on overactive bladder with 21270 attendees. As no individuals are named, we could not ascertain numbers of repeat attendees. Table 1 summarises event characteristics. Events focusing on these conditions represent $2.7 \%$ of sponsored events $(n=116845)$ over the 4 -year period and $2.8 \%$ of attendees $(n=3481750) .{ }^{12}$

For all three conditions, the median number of event attendees (19 to 20) was similar to sponsored events in general. ${ }^{12}$ For all three conditions, events were held less often in a clinical setting (hospital or clinic) than other sponsored events: relative risk $(\mathrm{RR})=0.51(95 \%$ CI 0.50 to 0.53 ) for depression; $\mathrm{RR}=0.72(95 \% \mathrm{CI} 0.68$ to 0.76 ) for osteoporosis; $\mathrm{RR}=0.47$ (95\% CI 0.43 to 0.50 ) for overactive bladder. Nurses were only at $24.4 \%$ of condition-focused events compared with $39.6 \%$ of total events, ${ }^{12}$ likely reflecting the less frequent hospital setting. However, attendees were more likely to be primary care physicians (GPs or family medicine) than at other events: $\mathrm{RR}=3.06$ (95\% CI 2.81 to 3.32) for depression, $\mathrm{RR}=1.48$ (95\% CI 1.41 to 1.55 ) for osteoporosis, and $\mathrm{RR}=2.59$ (95\% CI 2.09 to 3.21) for overactive bladder. Depression and osteoporosis events were 


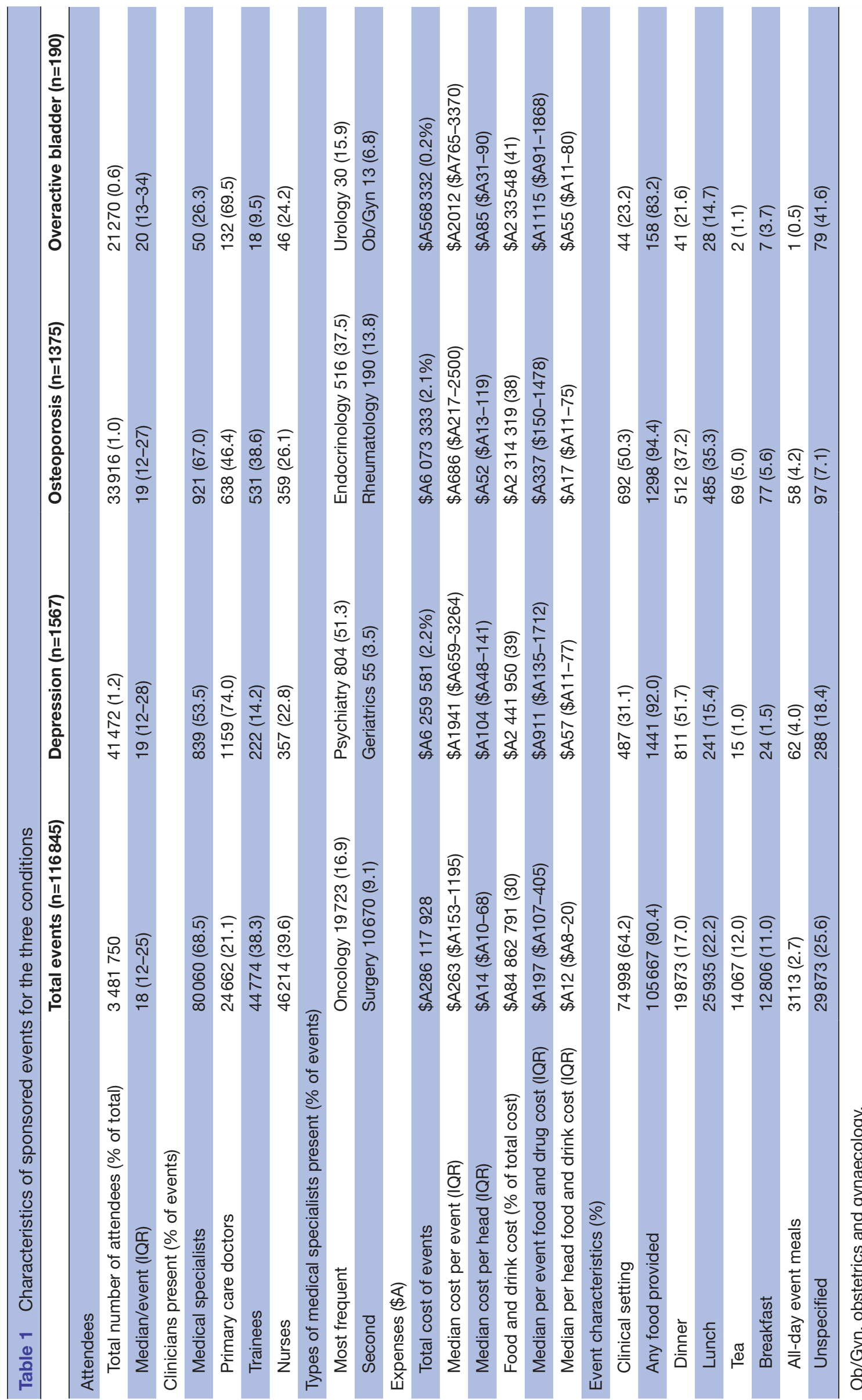


Total events

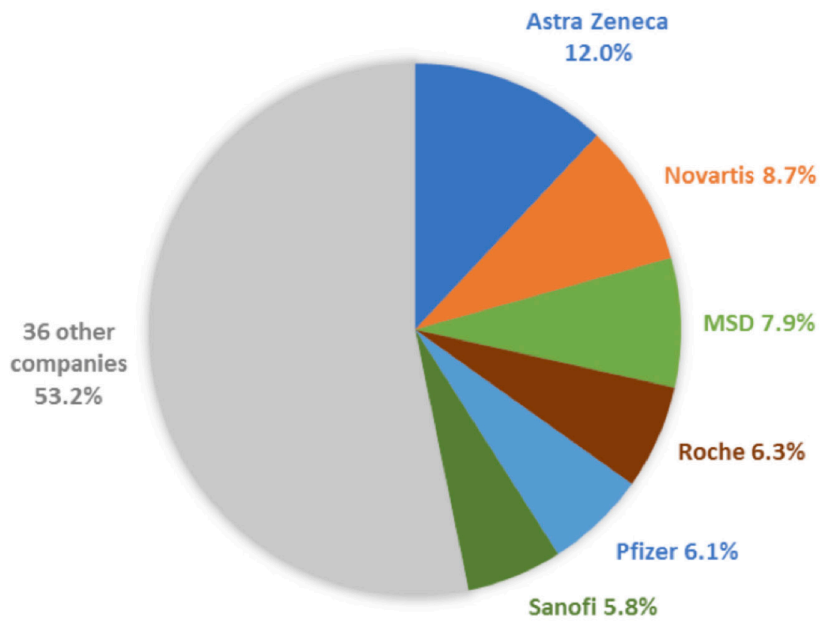

Osteoporosis

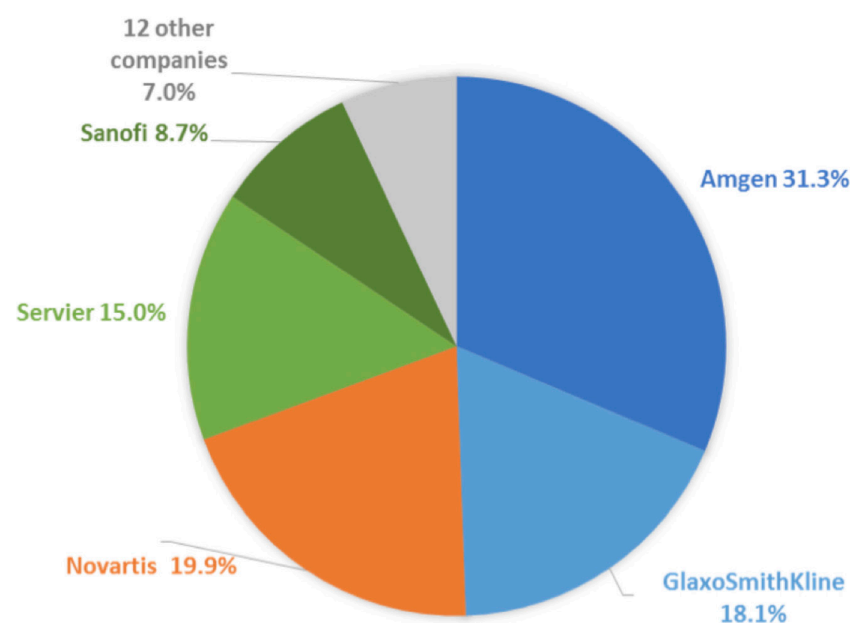

Depression

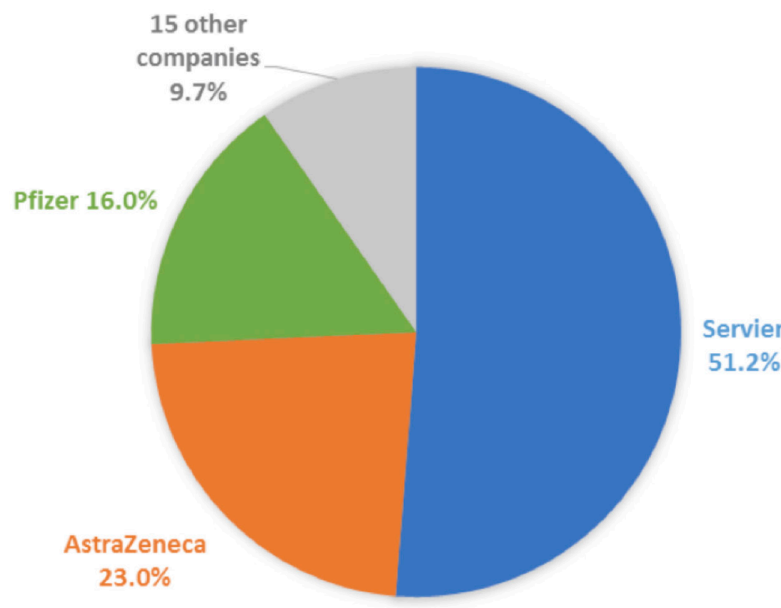

Overactive bladder

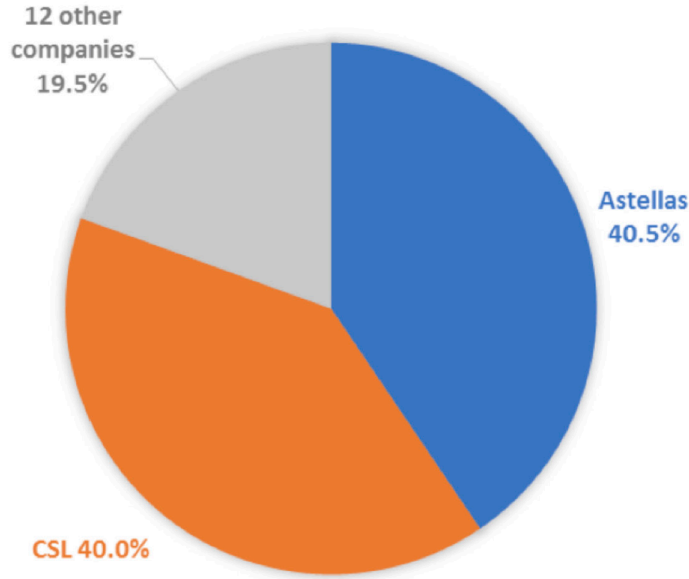

Figure 1 Per cent of events sponsored by each company, in total and per condition. Companies that sponsored at least $5 \%$ of events are listed.

also more likely to feature a dinner than other events: $\mathrm{RR}=1.73(95 \%$ CI 1.64 to 1.82$)$ for depression and $\mathrm{RR}=1.33$ (95\% CI 1.27 to 1.38 ) for osteoporosis. This trend was not seen for overactive bladder.

The median cost per attendee was higher than for events in general (\$A14): \$A104 for depression, \$A52 for osteoporosis and $\$ \mathrm{~A} 85$ for overactive bladder (table 1).

A few companies sponsored most of these condition-focused events. Figure 1 provides an overview of companies sponsoring $\geq 5 \%$ of events. All sell at least one drug for the relevant indication. Table 2 provides an overview of these drugs' PBS funding status. We present illustrative event descriptions featuring brand names in table 3, with added details on sponsored events per company in online supplementary appendix table 3 .

\section{Depression-related events}

Two companies sponsored $>80 \%$ of depression-related events: Servier (51.2\% of events), which markets the antidepressant agomelatine and AstraZeneca $(23.0 \%$ of events), which markets the antipsychotic quetiapine. The extended-release formulation of quetiapine (brand name Seroquel XR) is approved for depression treatment in patients intolerant to other therapies or with inadequate response. Neither agomelatine nor the depression indication for quetiapine are PBS subsidised. Pfizer, which markets five PBS-subsidised antidepressants (desvenlafaxine, venlafaxine, sertraline, reboxetine, doxepin), was the next most frequent sponsor ( $16.0 \%$ of events).

We examined agomelatine and quetiapine sales volumes over the study period. Agomelatine sales tripled, from 99625 units in 2012 to 300103 units in 2015 (28 days treatment/unit). Sales of the extended-release formulation of quetiapine increased from 247374 units in 2012 to 374917 in 2015 (60 days treatment/unit). Sales of other AstraZeneca quetiapine formulations decreased over the same period, from 499445 units sold in 2012 to 202783 in $2015^{23}$ (see online supplementary appendix figure 1.1). 


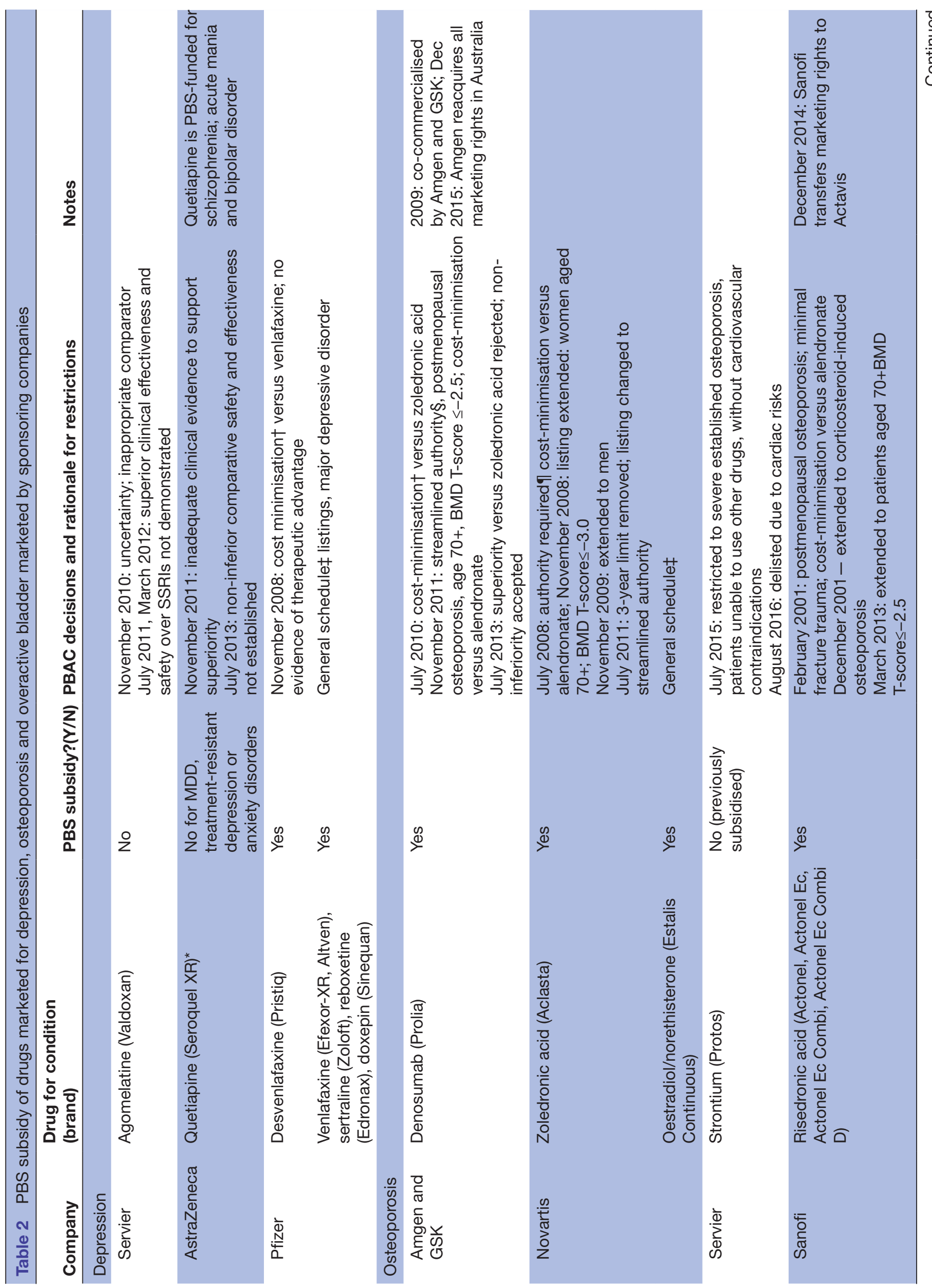




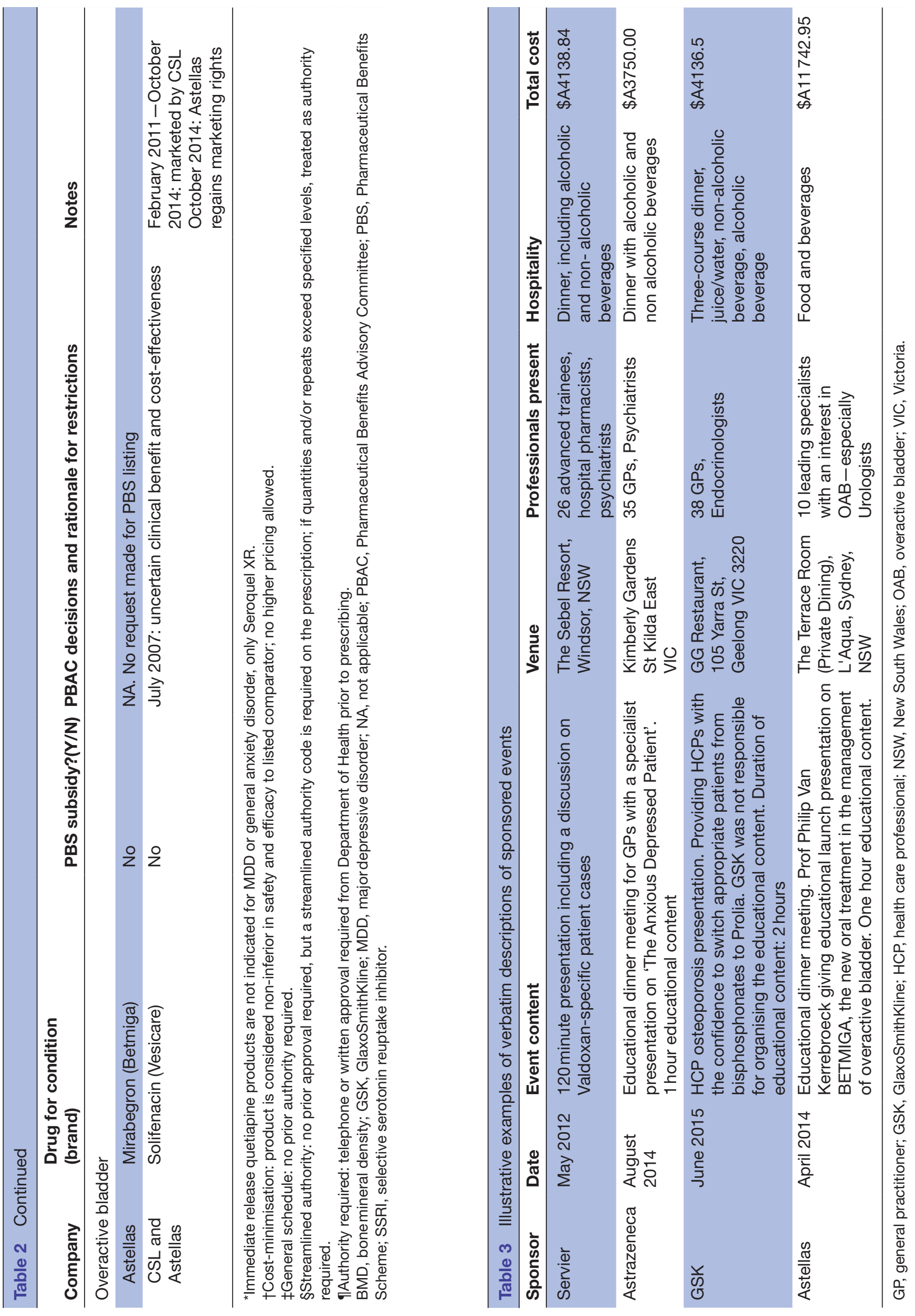

믕 


\section{The Anxious, Depressed Patient}

\author{
Dr lan Katz, \\ Consultant Psychiatrist, \\ Monash Hospital
}

Wednesday 6th August 2014 6.45pm-9.30pm

Kimberly Gardens

441 Inkerman Street, St Kilda Eas

\section{For more information, please contact one of your AstraZeneca representatives: Emily Armstrong on 0410589102 Brian Kent on 0434327898}

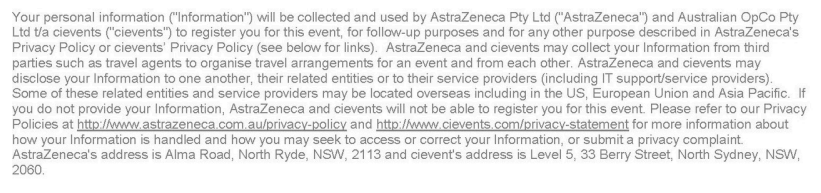

AstraZeneca Pty Ltd, Alma Road, North Ryde 2113
ABN 54009682311

Figure 2 Invitation for an AstraZeneca sponsored event.

Seventy-nine AstraZeneca events focused on 'the anxious depressed patient'. Figure 2 is an invitation for one of these events, featuring the same image that was used in an advertisement for extended-release quetiapine that appeared in the Medical Journal of Australia. This formulation of quetiapine is also indicated for generalised anxiety disorder.

\section{Osteoporosis-related events}

Osteoporosis event sponsorship, similarly, was highly concentrated: Amgen and GSK, which comarket denosumab, sponsored $31.3 \%$ and $18.1 \%$ of events respectively (in total, $49.4 \%$ ). Novartis, which markets zoledronic acid, and oestradiol/norethisterone, a hormone therapy approved for osteoporosis prevention in high-risk women intolerant of other products, sponsored 19.9\% of events; Servier, which markets strontium, sponsored $15.0 \%$; and Sanofi, which marketed risedronic acid until December 2014, sponsored 8.7\%. Denosumab, zoledronic acid, oestradiol/norethisterone and risedronic acid are PBS subsidised; strontium was delisted in August 2016 due to cardiac risks.

Sanofi transferred its marketing rights for risedronate to Actavis in December 2014. ${ }^{24}$ Sanofi sponsored

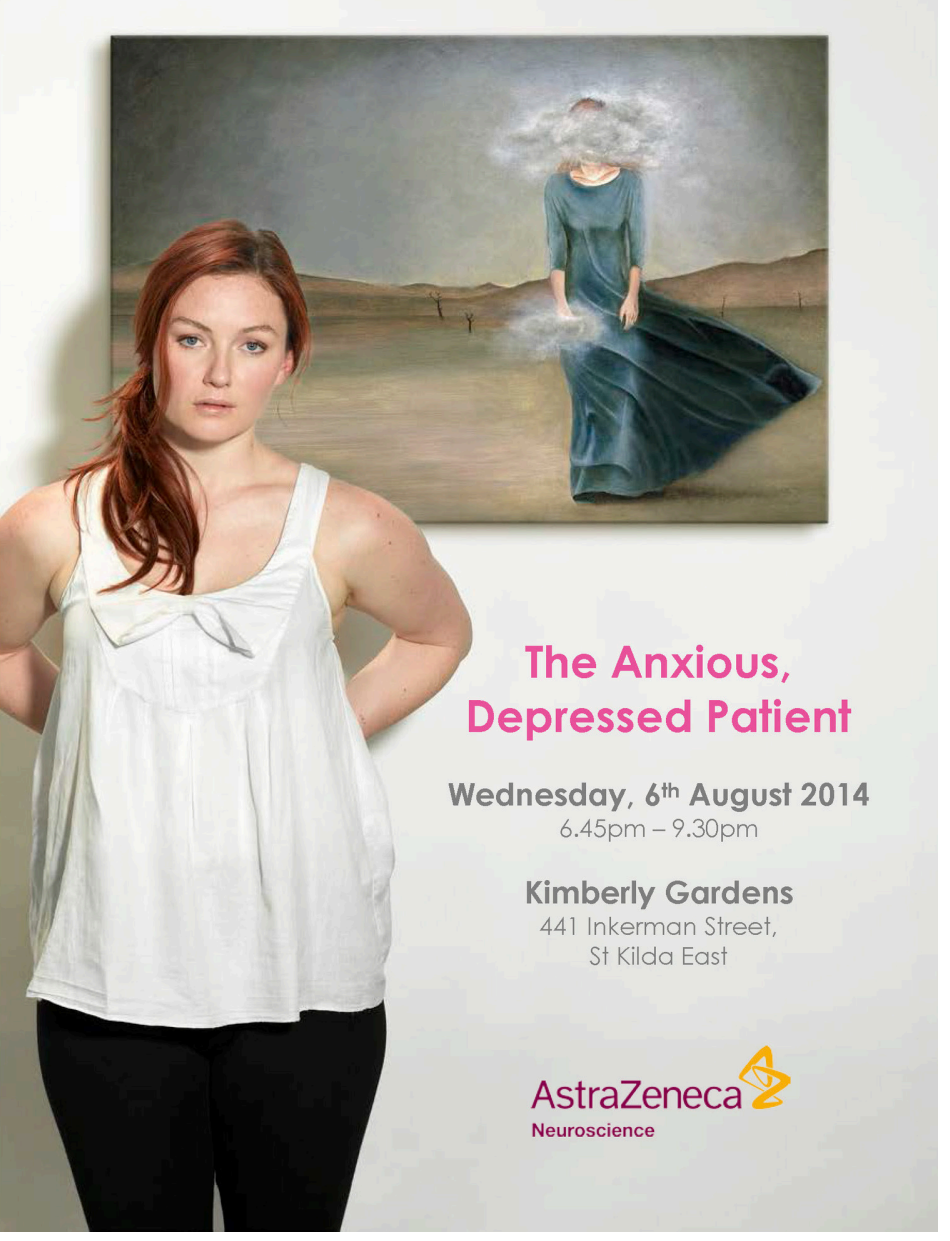

no osteoporosis events from October 2014 onwards (see online supplementary appendix figure 1.2).

Denosumab dispensations increased nearly sevenfold over the study period, from 45220 in 2012 to 309350 in 2015. ${ }^{25}$ Risedronate, zoledronic acid and strontium dispensations all decreased (see online supplementary appendix figure 1.3) Of 193 events mentioning denosumab's brand name, Prolia, 104 were sponsored by Amgen and 88 by GSK.

\section{Overactive bladder-related events}

Two companies dominated sponsorship of overactive bladder events: Astellas (40.5\% of events), which markets mirabegron and solifenacin, the latter after October 2014 and CSL ( $40.0 \%$ of events), which marketed solifenacin from February 2011 to October 2014. Neither drug is PBS subsidised. Astellas did not request PBS reimbursement for mirabegron. PBAC rejected solifenacin in 2007, judging benefits and cost-effectiveness to be uncertain.

All CSL-sponsored overactive bladder events occurred while the company held distribution rights for solifenacin to October 2014. Most Astellas-sponsored events were held from 2014 onwards, when it obtained marketing rights (see online supplementary appendix figure 1.4). 
Both solifenacin and mirabegron sales increased over the study period (see online supplementary appendix figure $1.5)$.

\section{DISCUSSION}

In this analysis of 3132 Australian pharmaceutical industry-sponsored events with 96660 attendees, focusing on three clinical conditions prone to overdiagnosis, we found a strong concentration of sponsorship among few companies. Two companies sponsored over $70 \%$ of depression events; another two companies over $80 \%$ of overactive bladder events. For osteoporosis, the two companies that comarket denosumab sponsored nearly $50 \%$ of events.

Several products marketed by key event sponsors were considered unacceptable for PBS reimbursement, and are associated with cost, efficacy and safety concerns that have been flagged internationally. Servier, which sponsored over half of depression-related events, sells agomelatine which is not PBS subsidised. Agomelatine is not approved in the USA or Canada. A French independent drug bulletin, Prescrire, characterised the drug as 'more dangerous than useful' and called for its withdrawal in $2015 .{ }^{26}$ A Spanish bulletin, similarly, considered it "worse than first-line antidepressants, up to 15-fold more expensive and a worrying hepatic safety profile. ${ }^{, 27}$

A 2012 Cochrane systematic review found that AstraZeneca's atypical antipsychotic quetiapine had limited efficacy evidence for depression. ${ }^{28}$ An updated systematic review, published in 2015, concluded that quetiapine had not been shown to improve function and that methodological biases had exaggerated benefits and minimised harm. ${ }^{29}$

Like agomelatine, denosumab is on the French bulletin Prescrire's list of 71 drugs to avoid in 2016 because of 'a disproportionate risk of adverse events' including serious infections due to immunosuppression, with only modest efficacy. ${ }^{30}$ In 2015, half of all new Australian osteoporosis prescriptions were for denosumab. ${ }^{31}$

All anticholinergic overactive bladder drugs, including solifenacin, have modest benefits, preventing one incontinence episode on average every 2 days, with frequent dry mouth and constipation, and there is observational evidence of dementia risk with longer term use. ${ }^{32}$ Mirabegron has similar efficacy to anticholinergics ${ }^{32}$ and can lead to severe hypertension. ${ }^{33}$

This analysis is limited by the data available. Our analysis only includes $2.7 \%$ of events, a likely underestimate as not all event descriptions mention a condition. These three conditions are illustrative case studies and cannot be assumed to represent all condition-related sponsored events. A variety of influences are expected to affect sales trends, including a large range of promotional activities. Sponsored events represent only one aspect of broader promotional campaigns to promote sales. ${ }^{34}$ However, a strength of this analysis is that it covers all sponsored events in Australia over 4 years, and coding was blinded to sponsor identity, types of attendees, gifts and costs. Due to the unique Australian dataset, this is the first such datadriven national analysis to examine condition-specific event sponsorship.

Company reports on financing of sponsored events provided limited information on content, leaving many questions unanswered. More research is needed on the messages in sponsored education, including on thresholds for disease diagnosis and treatment. Additionally, as individuals were not named, we could not directly evaluate the link between event attendance and individual prescribing patterns.

We could only examine potential contributions to overdiagnosis and overtreatment indirectly. We had hypothesised that events would focus on primary care, reflecting milder disease states. This is a hypothesised association only; we could not directly assess whether the messages in these events promote overdiagnosis or overtreatment. However, nearly two-thirds of events, $62 \%$, for the three conditions were attended by primary care doctors, versus $21 \%$ of other events. The focus on primary care was most pronounced for depression events: $74 \%$.

The concentration of sponsorship by companies marketing products subject to safety, cost and efficacy concerns raises questions about influences on prescribing choice. This pattern is consistent with Brody and Light's hypothesis of an 'inverse benefit law', in which intense marketing of drugs that may benefit a small proportion of patients is harmful to public health because a broader patient population is targeted than is likely to benefit. ${ }^{35}$

Many of these condition-focused events included dinner and were held in non-clinical settings such as restaurants. Costs per person were higher than for events in general. Even small gifts, such as food and drink, can affect behaviour. ${ }^{36}$ An analysis of US transparency reports found that physicians who receive one or more sponsored meals with a mean value of $<$ US $\$ 20$ were more likely to prescribe the promoted product, with larger effects observed the more meals received. ${ }^{37}$ We examined whether overseas travel may have been responsible for higher median costs. In total $(n=117845), 1.9 \%$ of events were held overseas, and as expected, these events had the highest per person costs. However, only $0.1 \%$ of depression-related events, $0.4 \%$ of osteoporosis-related events and no overactive bladder events were held overseas. Therefore, this is an unlikely explanation. Travel costs within Australia are not reported separately from other hospitality costs, so we could not examine their contribution to overall costs.

Timing of sponsorship was linked to when a company sold a drug to treat the included condition, consistent with a sales orientation. Companies discontinued event sponsorship of overactive bladder and osteoporosis events when they no longer had marketing rights for a product for these conditions. This promotional orientation is consistent with internal documents released during the US legal case on gabapentin, which described the use of CME to market off-label use. ${ }^{38}$ 
In this 4-year overview of industry-sponsored events focusing on depression, osteoporosis and overactive bladder, we found concentrated sponsorship among few companies per condition. These companies mainly market products that are not considered cost-effective choices for the specified conditions. This raises concerns about impacts on prescribing quality and on national prescribing trends. There was a strong focus on primary care physicians, frequent provision of dinner and non-clinical settings. Although a focus on primary care does not necessarily imply promotion of overdiagnosis, promotion in primary care is consistent with a focus on a broader rather than narrower patient population. This observed pattern of event sponsorship raises concerns about the role of industry-sponsored education in conditions identified as prone to overdiagnosis and highlights the need to ensure that professionals have ready access to continuing professional education that is free of commercial sponsorship.

\section{Author affiliations}

${ }^{1}$ Charles Perkins Centre and Faculty of Pharmacy, University of Sydney,

Camperdown, NSW, Australia

${ }^{2}$ Makassar Health Training Centre, Ministry of Health, Makassar, Indonesia ${ }^{3}$ Centre for Research in Medical Pharmacology, University of Insubria, Varese, Italy ${ }^{4}$ Faculty of Health Sciences and Medicine, Bond University, Robina, Queensland, Australia

Acknowledgements The authors would like to thank Quintiles IMS for their assistance in providing data on pharmaceutical sales volumes in Australia.

Contributors BM initiated the study, designed the data coding approach and plans for analysis, assisted with the development of the coding scheme, carried out analyses and drafted and revised the paper. She is the guarantor. SS and AF contributed to the study design and coding scheme, carried out data coding and analysis and revised the draft paper. QG, RM and LB contributed to the study design and coding scheme and revised the draft paper.

Funding Faculty of Pharmacy, The University of Sydney, provided summer scholarship funding for SS for the work contributed to this study.

Competing interests BM reported that she was an expert witness on behalf of plaintiffs in a Canadian class action suit concerning cardiovascular risks of a testosterone gel.

Patient consent Not required.

Provenance and peer review Not commissioned; externally peer reviewed.

Data sharing statement All data have been made publicly available and can be accessed at http://dx.doi.org/10.4227/11/592631edbd9d5.

Open Access This is an Open Access article distributed in accordance with the Creative Commons Attribution Non Commercial (CC BY-NC 4.0) license, which permits others to distribute, remix, adapt, build upon this work non-commercially, and license their derivative works on different terms, provided the original work is properly cited and the use is non-commercial. See: http://creativecommons.org/ licenses/by-nc/4.0/

Open data All data have been made publicly available and can be accessed at http://dx.doi.org/10.4227/11/592631edbd9d5.

(C) Article author(s) (or their employer(s) unless otherwise stated in the text of the article) 2018. All rights reserved. No commercial use is permitted unless otherwise expressly granted.

\section{REFERENCES}

1. Moynihan R. Doctors' education: the invisible influence of drug company sponsorship. BMJ 2008;336:416-7.
2. Marlow $\mathrm{B}$. Is continuing medical education a drug-promotion tool?: no. Can Fam Physician 2007;532:16504-6.

3. Meixel A, Yanchar E, Fugh-Berman A. Hypoactive sexual desire disorder: inventing a disease to sell low libido. $J$ Med Ethics 2015;41:859-62.

4. Fauber J, Jones C, Fiore K. Slippery slope: testosterone muscles its way to profits. Medpage Today 2015. http://www.medpagetoday. com/special-reports/slipperyslope/54156 (accessed 17 Jan 2017).

5. Spithoff S. Industry involvement in continuing medical education: time to say no. Can Fam Physician 2014;60:694700-3.

6. Hoffman JR, Cooper RJ. Overdiagnosis of disease: a modern epidemic. Arch Intern Med 2012;172:1123-4.

7. Moynihan R, Heath I, Henry D. Selling sickness: the pharmaceutical industry and disease mongering. BMJ 2002;324:886-91.

8. Moynihan R, Doust J, Henry D. Preventing overdiagnosis: how to stop harming the healthy. BMJ 2012;344:e3502.

9. Monk D. Improving transparency in the pharmaceutical industry. Aust Prescr 2016;39:110-1.

10. Robertson J, Moynihan R, Walkom E, et al. Mandatory disclosure of pharmaceutical industry-funded events for health professionals. PLoS Med 2009;6:e1000128.

11. Medicines Australia. Code of Conduct. 18th edn, 2015. https:// medicinesaustralia.com.au/wp-content/uploads/sites/52/2010/01/ 20150617-PUB-Code-Edition-18-FINAL.pdf

12. Fabbri A, Grundy Q, Mintzes B, et al. Pharmaceutical industryfunded events for health professionals: an analysis of data released under Australian transparency rules. BMJ Open 2017;7:e016701.

13. Dowrick C, Frances A. Medicalising unhappiness: new classification of depression risks more patients being put on drug treatment from which they will not benefit. BMJ 2013;347:f7140.

14. Järvinen TL, Michaëlsson K, Jokihaara J, et al. Overdiagnosis of bone fragility in the quest to prevent hip fracture. BMJ 2015;350:h2088.

15. Tikkinen KA, Auvinen A. Does the imprecise definition of overactive bladder serve commercial rather than patient interests? Eur Urol 2012;61:746-8.

16. AMH. Australian Medicines Handbook. Adelaide, Australia: AMH, 2016.

17. Jerant A, Kravitz RL, Fernandez Y Garcia E, et al. Potential antidepressant overtreatment associated with office use of brief depression symptom measures. J Am Board Fam Med 2014;27:611-20.

18. Mitchell AJ, Vaze A, Rao S. Clinical diagnosis of depression in primary care: a meta-analysis. Lancet 2009;374:609-19.

19. Wong J, Motulsky A, Eguale T, et al. Treatment indications for antidepressants prescribed in primary care in Quebec, Canada, 2006-2015. JAMA 2016;315:2230-1.

20. Organisation for Economic Cooperation and Development (OECD). Health at a Glance 2015: how does Australia compare? https:// www.oecd.org/australia/Health-at-a-Glance-2015-Key-FindingsAUSTRALIA.pdf (accessed 16 Jan 2017).

21. Elliott $\mathrm{C}$, Coat W, Hat B. Adventures on the dark side of medicine. Boston, MA, USA: Beacon Press, 2010.

22. Mintzes B, doctor' 'Ask your. 'Ask your doctor'. Women and direct to consumer advertising. In: Ford AR, Sabil D, eds. The push to prescribe: women and Canadian drug policy. Toronto: Women's Press, 2010:15-46.

23. QuintilesIMS. Quetiapine Fumarate unit sales in Australia, 2012 to 2015. Data provided to authors on request by QuintilesIMS. 2016.

24. Pharma Dispatch. Actavis takes back Actonel. 2014. https:// pharmadispatch.com/news/actavis-takes-back-actonel (accessed 9 Jan 2017).

25. Pharmaceutical Benefits Scheme. Australian Department of Health. ASM_Table_1. Australian Statistics on Medicine. 2012 to 2015. 2016. https://www.pbs.gov.au/info/browse/statistics (accessed 25 Jan 2017).

26. Prescrire Editorial Staff. Pour Mieux Soigner: des médicaments à écarter: bilan 2015. La Revue Prescrire 2015;35:144-51.

27. Anonymous. Worse than first-line antidepressants, up to 15fold more expensive, and a worrying hepatic safety profile. Drug assessment report drug and therapeutics bulletin of navarre. 2010. DAR no. 3 http://www.navarra.es/home_en/Temas/Portal+ de+la+Salud/Profesionales/Documentacion+y+publicaciones/ Publicaciones+tematicas/Medicamento/FET/2010/DAR+No+3+ Agomelatine.htm

28. Komossa K, Depping AM, Gaudchau A, et al. Second-generation antipsychotics for major depressive disorder and dysthymia. Cochrane Database Syst Rev 2010;12. CD008121.

29. Therapeutics Initiative. Antipsychotics should not be used for nonpsychotic depression. 2015. Therapeutics Letter 95 http://www.ti. 
ubc.ca/2015/09/30/antipsychotics-should-not-be-used-for-nonpsychotic-depression/ (accessed 16 Jan 2017).

30. Prescrire Editorial Staff. Towards better patient care: drugs to avoid in 2016. Prescrire Int 2016;25:105-11.

31. McColl G. Chair, drug utilisation sub committee. Drug utilisation committee outcome statement 29-30 september 2016. Canberra, Australia: Pharmaceutical Benefits Advisory Committee, Pharmaceutical Benefits Service, 2016. http://www.pbs.gov.au/ industry/listing/elements/dusc-meetings/dos/dusc-dos-sep-2016.pdf

32. Therapeutics Initiative. Are claims for newer overactive bladder drugs warranted? 2015. Therapeutics Letter 93 http://www.ti.ubc.ca/2015/ 04/22/are-claims-for-newer-drugs-for-overactive-bladder-warranted/ (accessed 26 Jan 2017)

33. Medicines and Health Products Regulatory Agency. Mirabegron (Betmiga): risk of severe hypertension and associated cerebrovascular and cardiac events. Drug Safety Update. 2015. https://www.gov.uk/drug-safety-update/mirabegron-betmiga-risk-of- severe-hypertension-and-associated-cerebrovascular-and-cardiacevents (accessed 20 Jan 2017).

34. Gagnon MA, Lexchin J. The cost of pushing pills: a new estimate of pharmaceutical promotion expenditures in the United States. PLoS Med 2008;5:e1.

35. Brody H, Light DW. The inverse benefit law: how drug marketing undermines patient safety and public health. Am J Public Health 2011;101:399-404.

36. Dana J, Loewenstein $\mathrm{G}$. A social science perspective on gifts to physicians from industry. JAMA 2003;290:252-5.

37. DeJong C, Aguilar T, Tseng CW, et al. Pharmaceutical industrysponsored meals and physician prescribing patterns for medicare beneficiaries. JAMA Intern Med 2016;176:1114-10.

38. Steinman MA, Bero LA, Chren MM, et al. Narrative review: the promotion of gabapentin: an analysis of internal industry documents. Ann Intern Med 2006;145:284-93. 